\title{
La discusión sobre el aborto en Chile
}

\author{
JUAN PABLO BECA I. ${ }^{1}$
}

1. Centro de Bioética, Facultad de Medicina Clínica Alemana Universidad del Desarrollo.

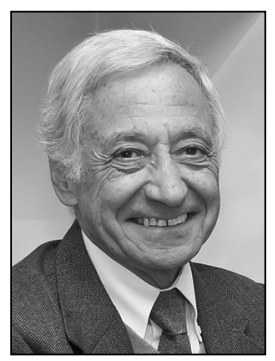

El problema del aborto ya no es el que existió en Chile hasta mediados de los años sesenta en que se hablaba de "epidemia" de abortos provocados que causaban más de 300 muertes maternas al año ${ }^{1}$. También han cambiado la visión y las legislaciones sobre derechos sexuales y reproductivos de la mujer en el mundo. Recientemente se ha abierto en el país una nueva discusión social, la que pronto será parlamentaria, sobre las condiciones y los alcances de una posible modificación de actual legislación para despenalizar o legalizar el aborto en algunas situaciones. Este tema, como en muchos países, genera mucha polémica y ella se realiza no sólo con sesgos por las diferencias de valores, creencias y experiencias, sino de manera muy polarizada por posiciones ideológicas, lo cual genera gran dificultad para aceptar las legítimas diferencias de opinión y para conseguir consensos mínimos. Los pediatras, si bien no nos enfrentamos a decisiones profesionales en el tema, somos consultados por nuestra condición de médicos y porque de alguna manera actuamos como consejeros genéticos, perinatales, familiares o de adolescentes embarazadas. Este breve análisis se presenta para contribuir a que cada pediatra adopte una posición personal debidamente fundamentada y razonada sobre el tema del aborto, junto a una actitud de respeto por las opiniones y decisiones de otros profesionales o de los pacientes.
La Organización Mundial de la Salud define el aborto como la interrupción del embarazo cuando el feto todavía no es viable fuera del vientre materno, lo cual equivale actualmente a un peso de nacimiento de menos de $500 \mathrm{~g}$ o a menos de 22 semanas de gestación. Sin embargo, en la actual discusión se ha hecho evidente que persiste confusión en las definiciones, razón por la cual se ha propuesto un glosario que unifique conceptos y favorezca un diálogo fructífero $^{2}$. En lo fundamental, y en particular para la propuesta legislativa, se considera terapéutico al aborto inducido con la intención de proteger la salud o la vida de la embarazada cuando éstas se encuentran en grave riesgo. Las otras dos condiciones en que la mayoría de las legislaciones lo autoriza son el aborto eugenésico, que es el inducido con la intención de evitar el nacimiento de un niño severamente malformado o portador de una anomalía fetal incompatible con la vida post-natal, y el aborto por abuso sexual que se refiere al aborto inducido de un embarazo como consecuencia de un hecho denunciado y constitutivo del delito de violación o de incesto.

Mundialmente se estima que ocurren 42.000.000 de abortos provocados al año, 48\% de los cuales son inseguros, la gran mayoría de los cuales ocurre en países del tercer mundo, con alta mortalidad ${ }^{3}$. El número de abortos no se conoce de manera confiable y las cifras de

Recibido el 16 de junio de 2014, aceptado para publicación el 06 de agosto de 2014.

Correspondencia a:

Juan Pablo Beca I.

E-mail:.jpbeca@mi.cl 
egresos hospitalarios por aborto incluyen tanto abortos espontáneos como complicaciones de abortos inducidos. En Chile, los egresos por esta causa son del orden de 30.000 al año por lo que se estima que habría 90.000 abortos anuales. Sin embargo, la mortalidad materna por aborto no pasa de 4 casos al año. Existe una relación inversa entre el acceso a control de natalidad y el número de abortos en un país, hecho que quedó claramente demostrado en Chile a partir de 1965 en que se introdujo la anticoncepción en la atención primaria de salud, seguida de una significativa disminución de la mortalidad materna. Los métodos abortivos son variados y en años recientes ha aumentado el acceso al aborto inducido por fármacos con lo cual disminuyen las complicaciones para la mujer.

El aborto constituye una realidad en todos los países y, por lo tanto, su discusión es una necesidad, especialmente en las sociedades contemporáneas que son plurales y no reconocen códigos morales únicos o impuestos por autoridades. De esa discusión social debería surgir una legislación que refleje la opinión ciudadana mayoritaria. Las leyes respectivas son por lo tanto diferentes en cada país y la gran mayoría de ellas respeta la vida antenatal rechazando el aborto como forma de regulación de la natalidad, permitiéndolo sólo ante situaciones calificadas y con plazos definidos, condiciones que varían de un país a otro. Muy pocos países, entre ellos Noruega, Suecia, algunos Estados en EE.UU. y recientemente Uruguay, aceptan el aborto libre o a demanda, y sólo 6 países prohíben el aborto inducido por cualquier causa: Chile, El Salvador, Nicaragua, República Dominicana, Malta y El Vaticano. En nuestro país, desde 1989 el aborto está legalmente prohibido y penalizado por la modificación del artículo 119 del Código Sanitario que actualmente dice "No podrá ejecutarse ninguna acción cuyo fin sea provocar un aborto" ". Con esta modificación, se eliminó la autorización para interrumpir el embarazo con fines terapéuticos que antes contemplaba esa norma, por lo que esta práctica puede quedar sujeta a las sanciones que fija el Código Penal en esta materia.

Recientemente en Chile el Gobierno ha anunciado que propondrá legislar sobre el aborto, sea a través de un nuevo proyecto de ley o patrocinando alguno de los cuatro proyectos de iniciativa parlamentaria previamente presentados. Estas propuestas coinciden en despenalizar el aborto, es decir hacerlo no punible, en situación de grave riesgo de vida o de salud de la embarazada, feto no viable, y ante embarazos por violación. Resulta evidente que cada una de estas tres situaciones requiere ser precisada, lo cual será motivo de discusión parlamentaria en su oportunidad, debiendo contar con la mejor asesoría posible de los especialistas que correspondan.

La realidad actual es que en Chile, de acuerdo con la lex artis de la práctica médica, se interrumpe el embarazo en los casos extremos de riesgo de vida de la madre pero se evita llamar aborto a estas interrupciones. Las decisiones se toman con dudas y temor, tardíamente y consultando innecesariamente a comités de ética o a los abogados institucionales. La razón es que la interrupción de un embarazo antes de las 22 semanas de gestación está tipificada como delito en nuestro Código Penal $\mathrm{y}$, aunque en la práctica no se penaliza, podría ser causa de denuncia judicial. Falta pues un marco de seguridad legal y judicial que permita decisiones médicas adecuadas, oportunas y no penalizadas ${ }^{5,6}$. Otros escenarios, probablemente menos categóricos que el anterior son el de la mujer que está gestando a un hijo severamente malformado o no viable después de su nacimiento, o el de la portadora de un embarazo producto de una violación confirmada o de incesto. Estos casos dramáticos no tienen respuesta en la actual legislación, aunque la opinión mayoritaria de los chilenos justifica el aborto en esas situaciones ${ }^{7}$. El principal argumento que se aduce para el rechazo del aborto bajo cualquier circunstancia es que ante el conflicto de valores entre la protección de la vida fetal y el derecho a decidir de una mujer se debería optar por la defensa de la vida del que está por nacer. En el otro extremo, quienes defienden el aborto libre lo hacen basados en el derecho de la mujer a disponer de su propio cuerpo. Aunque nadie está abiertamente en contra de la protección de la vida humana ni de la libertad de la mujer, el problema está 
en que los juicios morales, para ser razonables, deben admitir excepciones y requieren hacerse cargo de situaciones concretas y frecuentes como las señaladas. Esto es lo que se busca al aceptar que la legislación elimine la penalización del aborto ante situaciones debidamente precisadas. En otras palabras equivale a aceptar un mal menor ante situaciones en las cuales no existe una solución óptima que sea aceptada por todos.

Ante una posible modificación de nuestra legislación sobre el aborto, en la discusión actual tan enormemente polarizada, se ha hecho evidente el temor de algunos a que una despenalización del aborto ante casos excepcionales pueda abrir la puerta a futuras disposiciones excesivamente liberales. La respuesta frente a este temor es que la legislación debe reflejar la opinión mayoritaria de una sociedad, que permitir excepciones a la penalización no obliga a nadie a actuar de esa manera, y que futuras posibles modificaciones deberán ser discutidas en su oportunidad. También se ha argüido acerca del derecho a la objeción de conciencia y se le ha confundido con el derecho de las instituciones a tener su propia regulación. Ante este argumento es importante precisar que la objeción de conciencia es un derecho personal a rechazar el cumplimiento de determinadas normas jurídicas por considerarse éstas contrarias a las creencias éticas o religiosas. No puede entenderse como un derecho colectivo, pero las instituciones pueden definir sus normas por acuerdos internos conforme a su misión, respetando las objeciones de conciencia de sus profesionales y el marco jurídico vigente.

La literatura médica chilena ha publicado relativamente poco sobre el tema del aborto. La Revista Chilena de Pediatría publicó un documento del Comité de Ética de la Sociedad Chilena de Pediatría en $1999^{8}$. En los últimos 15 años se han publicado en Chile 91 artículos que se refieren al aborto, de los cuales 22 son en revistas médicas, la mayoría de los cuales se refiere a abortos espontáneos, a causas médicas específicas o a opiniones personales. El aporte de estas publicaciones a la actual discusión social y legislativa resulta por lo tanto insuficiente.

Los pediatras necesitan desarrollar más sensibilidad y alerta ética ante el drama humano del aborto, reconocer los inevitables sesgos personales y respetar las diferentes opiniones profesionales o ideológicas. En base a esta actitud cada pediatra necesita asumir una posición personal fundamentada y no ampararse sólo en la letra de la ley, lo que es tan frecuente en nuestro afán legalista que reduce el tema a lo que está permitido o no permitido en una ley o en su reglamento. Cabe recordar que los profesionales, en este caso los pediatras, tenemos un deber de apoyar y de educar a nuestros pacientes y sus familias, sin juzgar sus criterios o decisiones.

\section{Referencias}

1.- Castro R: Iniciativa FIGO de prevención del aborto inseguro: visión desde el Ministerio de Salud. Rev Chil Obstet Ginecol 2009; 74: 73-6.

2.- Centro de Bioética, Fac. Medicina Clínica Alemana Universidad del Desarrollo. Glosario para la discusión sobre el aborto, 2014. Disponible en http://medicina. udd.cl/centro-bioetica/files/2014/05/ABORTO-GLOSARIO.pdf

3.- Singh S, Wulf D, Hussain R, et al: Abortion worldwide: a decade of uneven progress,. Guttmacher Institute, 2009. Disponible en http://www.guttmacher.org/pubs/ Abortion-Worldwide.pdf

4.- Ley num. 18.826, 1989. Sustituye artículo 119 del Código Sanitario.

5.- Besio M: Aspectos bioético del aborto en Chile (1). Rev Chil Obstet Ginecol 2013; 78: 256-8.

6.- Molina R: Aspectos bioéticos del aborto en Chile (2). Rev Chil Obstet Ginecol 2013; 78: 259-61.

7.- Dides C, Benavente MC, Sáez I: Estado del arte sobre aborto en Brasil, Chile, México y Nicaragua. Editorial Flacso-Chile 2011. Disponible en http://issuu.com/ flacso.chile/docs/estado_del_arte_parte1.

8.- Comité de Etica Sociedad Chilena de Pediatría: El aborto terapéutico. Rev Chil Pediatr 1999; 70: 86-7. 